\title{
Methods for Assessing the Quality of Biomedical Cell Products for Skin Replacement
}

DOI: $10.17691 / \mathrm{stm} 2019.11 .4 .04$

Received August 6, 2019

D. Ya. Aleynik, PhD, Senior Researcher, Laboratory of Regenerative Medicine, Institute of Experimental Oncology and Biomedical Technologies ${ }^{1}$;

E.V. Zagaynova, MD, DSC, Professor of the Russian Academy of Sciences, Director of the Institute of Experimental Oncology and Biomedical Technologies';

M.N. Egorikhina, PhD, Senior Researcher, Laboratory of Regenerative Medicine, Institute of Experimental Oncology and Biomedical Technologies';

1.N. Charykova, Physician, Laboratory of Biotechnology, University Clinic';

O.S. Rogovaya, PhD, Researcher, Laboratory of Cell Biology2; Researcher, Department of Regenerative Medicine, Research Institute of Translational Medicine;

Yu.P. Rubtsova, PhD, Researcher, Laboratory of Regenerative Medicine, Institute of Experimental Oncology and Biomedical Technologies';

A.N. Popova, PhD Student, Department of Embryology, Faculty of Biology4; Engineer, Research Institute of Translational Medicine;

E.A. Vorotelyak, DSc, Corresponding Member of Russian Academy of Sciences, Head of the Laboratory of Cell Biology²; Head of the Department of Regenerative Medicine, Research Institute of Translational Medicine; Associate Professor, Department of Cell Biology and Histology, Faculty of Biology ${ }^{4}$

${ }^{1}$ Privolzhsky Research Medical University, 10/1 Minin and Pozharsky Square, Nizhny Novgorod, 603005, Russia;

${ }^{2}$ N.K. Koltsov Institute of Developmental Biology, Russian Academy of Sciences, 26 Vavilova St., Moscow, 119334, Russia;

${ }^{3}$ Pirogov Russian National Research Medical University, 1 Ostrovitianova St., Moscow, 117997, Russia;

${ }^{4}$ Lomonosov Moscow State University, 1 Leninskie Gory, Moscow, 119991, Russia

The aim of the study was the development of methods to assess the quality of biomedical cell products (BMCPs) intended to replace skin defects.

Materials and Methods. The proposed equivalent of the skin BMCP-1 (developed at the N.K. Koltsov Institute of Developmental Biology, Russian Academy of Sciences) and the BMCP-2 equivalent of the skin (developed at the Privolzhsky Research Medical University) were studied. Mesenchymal stem cells (MSCs) from human adipose tissue served as the cellular components of both BMCPs.

MSCs in suspensions and in BMCPs were tested for cell counts and cell viability. The BMCPs were studied in their entirety without destruction using fluorescence microscopy with vital dyes for staining the cytoplasm and Hoechst 3334 (BD Pharmingen, USA) — for nuclei (imager Cytation 5; BioTek, USA).

The MSC function was evaluated by their ability to produce VEGF-A. The MSC phenotype was determined by cytometry.

Results. Using the above methods, we found that MSCs in BMCP retained their original morphology and viability. On the surface of BMCP-1, cells are organized in colonies, whereas in the structure of BMCP-2, they are scattered throughout the matrix. The number of cells in BMCP-1 depends on the transportation conditions; and in the structure of BMCP-2 - on the timing of cultivation. The secretory activity of MSCs is maintained throughout the entire observation period.

While within the BMPC structures, the MSCs had their CD90 expression decreased; it was then restored after the cells were isolated from the products and cultivated on the plastic surface.

Conclusion. The proposed method is feasible for the BMCP quality assessment; it incorporates the requirements for production and transportation based on the characteristics of the cellular and non-cellular components. Given the optical non-transparency and complex physical-chemical structure of the product, it is advisable to select the quality control methods that ensure minimal manipulation and enzymatic damage.

Key words: biomedical cell product; mesenchymal stem cells; skin defects; proliferation; VEGF-A; phenotyping; CD90.

\section{Introduction}

Biomedical cell products (BMCPs) are an important object of domestic and international research with a special interest in their quality, safety, and effectiveness
[1]. It is, therefore, relevant to establish the commonly accepted criteria and methods for assessing such products as emphasized in the Federal Law "About biomedical cell products" [2].

To date, in the Russian Federation, there is

Corresponding author: Diana Ya. Aleynik, e-mail: daleynik@yandex.ru 
no practical experience of conducting the quality assessment procedure for BMCP. The quality indicators of a BMCP must be compatible with its specifications [3]. Usually, the set of such indicators is determined by the manufacturer. Some potentially useful methods for BMPC characterization are described in the guidelines, edited by V.A. Tkachuk (2017) [4]. However, due to the fact that the newly developed BMCPs have varying physical structures, as well as varying chemical and cellular compositions, their quality control methodology may need more than one approach.

This study examines dermatotropic BMCPs. The conditionally controlled parameters of such a product can be divided into three groups:

1) visual characteristics (integrity of the package, correct and complete labeling, conformity of the external appearance and the transportation conditions as declared in the specification);

2) parameters characterizing the product sterility and the absence of contamination by mycoplasmas and viruses;

3) parameters of the cell lines (cell viability, concentration, cell line identification, functional activity of cells).

To characterize the cellular component of a BMCP product, it is necessary to transfer the cells from the BMCP into the culture medium. The process of separating the cells from the matrix, as a rule, requires matrix decomposition; this procedure may lead to a partial cell loss and adversely affect the remaining cells. On the other hand, the methods proposed to characterize the cellular component directly in the BMCP matrix without cell isolation require specific development for each type of BMCP. All methods recommended for assessing the quality of a product should be specified in the product dossier.

The aim of the study was the development of methods to assess the quality of biomedical cell products intended to replace skin defects.

\section{Materials and Methods}

In this study, we used samples of two domestic BMCPs designed for the skin defect replacement that were undergoing preclinical studies.

BMCP-1 - a dermal equivalent of the skin had been designed at the N.K. Koltsov Institute of Developmental Biology, Russian Academy of Sciences (Moscow). In this product, the non-cellular component is represented by the medical product (plate) G-derm (RU No.RZN $2015 / 3135$ ), consisting of a structured mixture of low molecular weight hyaluronic acid (about 90\%) and type I collagen (about 10\%) The cellular component is represented by surface-plated allogeneic mesenchymal stem cells (MSCs) from human adipose tissue.

BMCP-2 is a skin equivalent designed at the Privolzhsky Research Medical University (Nizhny Novgorod). This product is based on a hydrogel scaffold from natural biopolymers - fibrinogen of the blood plasma and type I collagen in a ratio of 22:1 [5]. The cellular component of BMCP-2 is represented by cultured allogeneic MSCs incorporated into the product during its formation.

The cellular components of both BMCPs are represented by MSCs from human adipose tissue. Over the past decades, these cells have attracted attention as the most promising cellular material for regenerative medicine [6]. The International Society for Cell Therapy (ISCT) has proposed the main requirements for MSCs: adhesion to the plastic surface, expression of specific markers, ability to differentiate into osteoblasts, adipocytes, and chondroblasts in vitro [7]. All MSC lines used in this study for the formation of BMCP met the criteria defined by the ISCT.

Before testing, samples of BMCP-1 were packed in a special medium and transported for $12-24 \mathrm{~h}$ to the laboratory that performed the analysis; BMCP-2 was made directly in this laboratory.

Cell count and viability assessment in cell suspensions and in BMCP matrices

Counting the living cells in suspension using the trypan blue exclusion method. The cells were removed from the surface of a G-derm plate in the standard way using $0.25 \%$ trypsin in Versen's solution (PanEco, Russia), washed with PBS and pelleted; the resulting suspension was stained with $4 \%$ trypan blue solution for 2-3 min. During this time, nonviable cells with damaged membranes become evenly stained whereas living cells remain unstained. The number of living (unstained) and dead (stained) cells was counted in a hemocytometer or using a Countess cell counter (Invitrogen, USA).

Determination of viable cells in a BMCPattached culture by staining with the vital fluorescent dye - calcein. Before the staining (Calcein AM; BD Pharmingen, USA) was diluted in PBS at a ratio of 1:3000. The solution was then added to the plate wells to replace the culture medium. Samples with the fluorochrome solution were incubated for $30 \mathrm{~min}$ in a $\mathrm{CO}_{2}$ incubator at a temperature of $37^{\circ} \mathrm{C}$, then washed with phosphate buffer and subjected to microscopic examination.

Total cell count in the BMCP-attached culture by the number of nuclei stained with Hoechst 3334. An original method was used to count the cells retained in the BMCP-2 structure [8]. It is based on intravital nuclei staining with the Hoechst 3334 fluorescent dye (BD Pharmingen, USA) followed by wide-field fluorescence microscopy in the Z-stack mode and subsequent counting of cell nuclei on crosslinked Z-stack microphotographs. The quantification was performed on days 1, 3, and 6 after BMCP-2 had been formed (day 0 ). To that end, fragments with an area of $0.64 \mathrm{~cm}^{2}$ were separated from the BMCP-2 sample at the predefined time points and transferred to a 24-well Black Visiplate TMTC plate (Wallac Oy, 
Finland). The separated fragments were stained with Hoechst 3334 followed by nuclei counting. After the separation of fragments, BMCP-2 samples were further cultured for up to 6 days in a humidified $5 \% \quad \mathrm{CO}_{2}$ incubator under $37^{\circ} \mathrm{C}$, with medium replacement every 2-3 days.

Cell staining with fluorescent membrane dyes to assess the morphology of MSCs inside the BMCP structure. To stain the membranes of cells contained in the BMCP, the fluorochrome Lipophilic Tracers-DiO DiOC14 (3) Hydroxyethanesulfonate (Biotium, USA) was used. In accordance with the manufacturer's recommendations, aliquots of the dye were added to the growth medium in a ratio of 1:2000 in wells with BMPC samples and incubated for 30$40 \mathrm{~min}$ to provide for uniform membranes staining. The washed cells were then studied using a wide-field fluorescence microscope equipped with a Cytation 5 multifunction imager (BioTek, USA) combined with the Gen5 Imedge+ software. The resulting microphotographs were used to document and save the obtained data.

Quantification of VEGF in the growth medium. To determine the secretory activity of MSCs within the BMCP, we measured their ability to produce VEGF-A factor (from the family of vascular endothelial growth factor, VEGF).

Sampling was carried out within 3 days after the BMCP-1 formation, as the final product was intended for use within 3 days. To do that, BMCP-1 samples sized at $1 \mathrm{~cm}^{2}$ were placed in wells of a 24 -well plate and incubated for 24,48 , and $72 \mathrm{~h}$. Then, $50 \mu \mathrm{l}$ of the growth medium was taken to determine the VEGF content.

In the study of BMCP-2, considering the slower adjustment of the cells to the matrix, samples of the growth medium were taken on the $3^{\text {rd }}, 5^{\text {th }}$, and $7^{\text {th }}$ days after the product formation. As a control, MSCs of the same lines and passages were cultured in a 24well plate in the standard way. Samples of the growth medium taken before the start of the study served as a mandatory control: for BMCP-1, those were aliquots of the medium in which cell-free G-derm plates were incubated; for BMCP-2, that was the medium in which the cell-free scaffold samples were incubated.
Concentration of VEGF-A was quantified with ELISAbased reagent kits from Invitrogen, Thermo Ficher Scientific (USA, Canada). The optical density was measured using a Sunrise analyzer (TECAN, Austria) with the Magellan software.

Phenotyping of MSC cultures. The immunophenotype of adipose tissue MSCs contained in BMCPs was determined with the help of a BD FACS CANTO II cytofluorimeter (Becton Dickinson, USA). A panel of monoclonal antibodies from Beckman Coulter and Becton Dickinson (USA) was used: CD90 FIC, CD105 PE, 73 PE, 44 FITC, 45 PC5, CD14 PC5, CD HLA-DR PC7, CD34 PC7 with the corresponding isotypic controls.

To determine the cell immunophenotype in BMCP-1, cells were removed from the plate surface with trypsin; in BMCP-2, the hydrogel scaffold was decomposed by enzymatic treatment with type 1 collagenase (SigmaAldrich, USA).

Statistical analysis. All measurements were performed in at least 3 replicates. The results were processed using nonparametric statistics (Wilcoxon paired comparison) and the Statistica 6.0 software package.

\section{Results and Discussion}

\section{Cell count and viability assessment in cell suspensions and in BMCP matrices}

Counting the viable cells in suspension by the trypan blue exclusion method. The counts of adipose tissue MSCs harvested from the BMCP-1 surface differed between the 6 experiments where the initial cell density was either $20 \cdot 10^{3}$ or $30 \cdot 10^{3} / \mathrm{cm}^{2}$ and the time of incubation was either 36 or $48 \mathrm{~h}$ (Table 1 ).

The data analysis revealed that the final cell number depended on their initial cell density, on the time elapsed after the BMPC formation, on the fixation procedure, and on the transportation conditions. In addition, the number of cells in the tested samples might be influenced by some displacement of the samples inside the wells. In such cases, microscopy revealed that a sizable number of cells remained attached to the well bottom and walls and, apparently, were not be removed by the harvesting procedure (Figure 1).

Table 1

The numbers of cells in BMCP-1 samples

\begin{tabular}{ccccccc}
\hline $\begin{array}{c}\text { Experiment } \\
\text { No. }\end{array}$ & $\begin{array}{c}\text { Number } \\
\text { of samples }\end{array}$ & $\begin{array}{c}\text { Cultured } \\
\text { for }(\mathrm{h})\end{array}$ & $\begin{array}{c}\text { Initial density } \\
\left(\times 1000 / \mathbf{c m}^{2}\right)\end{array}$ & $\begin{array}{c}\text { Total number } \\
\text { of cells }\end{array}$ & $\begin{array}{c}\text { Number } \\
\text { of sample-attached } \\
\text { cells }\left(\times 1000 / \mathbf{c m}^{2}\right)\end{array}$ & $\begin{array}{c}\text { Cells } \\
\text { under the samples }\end{array}$ \\
\hline 1 & 5 & 48 & 30 & 323 & 64.6 & + \\
\hline 2 & 2 & 48 & 30 & 127 & 63.5 & + \\
\hline 3 & 5 & 48 & 20 & 200 & 40 & + \\
\hline 4 & 8 & 36 & 20 & 202 & 25.3 & +++ \\
\hline 5 & 16 & 48 & 20 & 526 & 39 & + \\
\hline 6 & 5 & 36 & 20 & 111 & 22.2 & +++ \\
\hline
\end{tabular}


Figure 1. The state of BMCP-1 after transportation:

viable MSCs of adipose tissue (arrows) on the well surface next to the G-derm matrix after transportation in a sealed package for $24 \mathrm{~h}$; light microscopy, $\times 100$
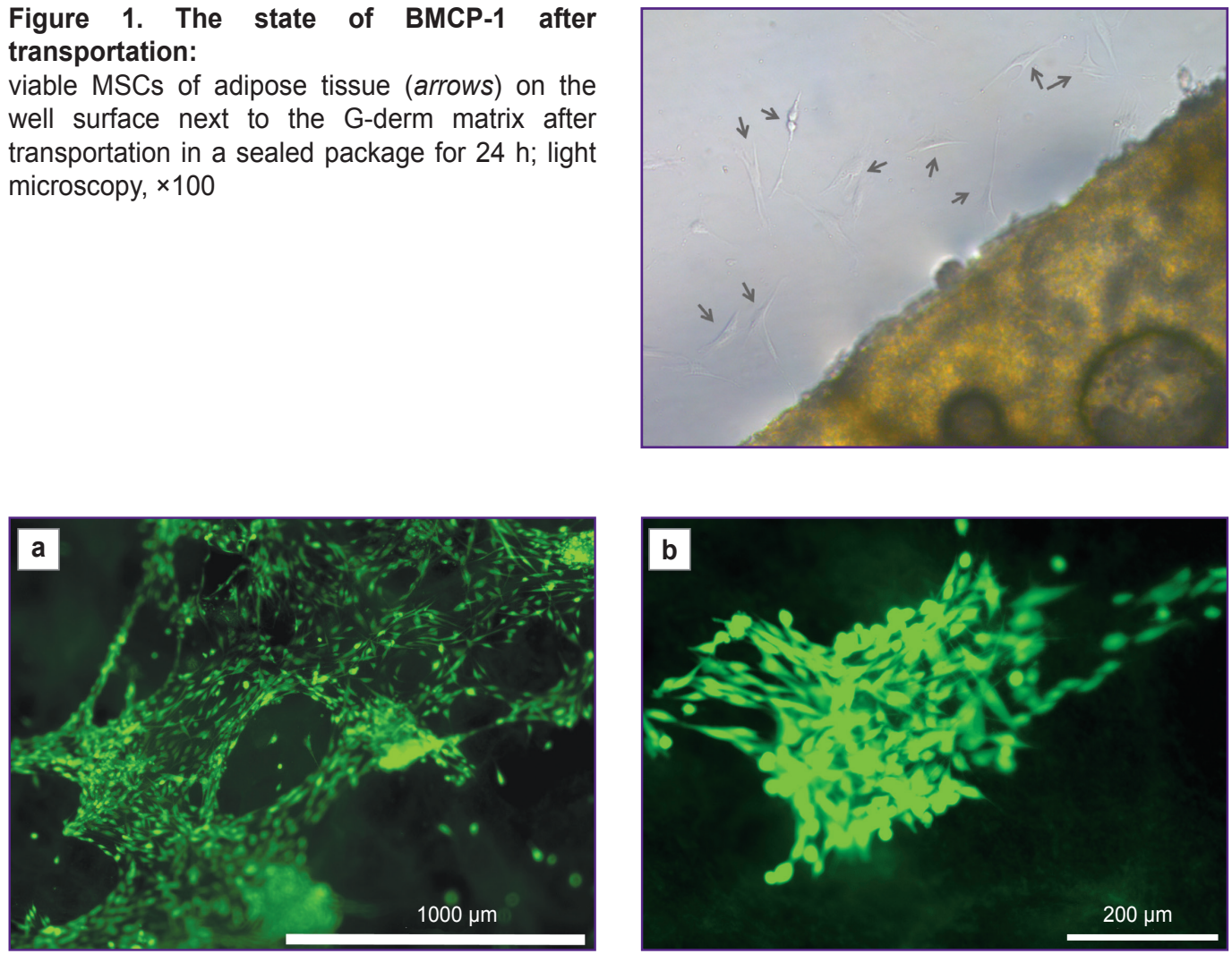

Figure 2. Visualization of cells contained in BMCP-1:

viable MSCs stained with calcein (green staining) on the G-derm surface; fluorescence microscopy, excitation $-477 \mathrm{~nm}$, emission $-525 \mathrm{~nm}$; (a) $\times 40$; (b) $\times 100$

In all batches, the viability of cells isolated from the surface of G-derm plates was not less than $98 \%$.

Cells spread over the surface of the BMCP-1 were easily detached by trypsinization and counted in a standard hemocytometer to determine the number of viable cells. However, the enzymatic treatment could lead to partial destruction, loss or damage of those cells, thus resulting in a measurement error; that factor should be taken into account when analyzing the obtained data.

Determination of viable cells in the BMCP. attached culture by staining with the vital fluorescent dye - calcein. When visualizing cells from the BMCP-1, it was clearly seen that the cells on the surface of the G-derm plate were spread unevenly, and most of them were present in the form of colonies (Figure $2(a),(b))$. The cells showed a typical fibroblastlike morphology with well-expressed processes. Varying numbers of colonies were detected in different samples, but no monolayer formation was observed. We assume that this pattern of MSC distribution over the G-derm plate reflected the heterogeneous topography of this plate.

Total cell count in the BMCP-attached culture by the number of nuclei stained with Hoechst 3334. Fluorochrome-labeled cell nuclei were well visualized inside the BMCP-2 structure (Figure 3 ).
Quantification of these nuclei demonstrated a statistically significant increase in the number of cells within the BMCP-2 structure during cultivation (Table 2).

Table 2 shows that the number of cells in BMCP-2 changed similarly in all three series and did not vary between the MSC lines used to form the construct.

As the MSCs become an integral part of the final BMCP-2 product, their isolation requires a complete destruction of the non-cellular component by using the aggressive enzymatic treatment (trypsin, collagenase) with a high risk of cell loss or damage. The developed method [8] though made it possible to conduct a quantitative analysis of the cellular component without cell destruction and with high accuracy of the results.

Cell staining with fluorescent membrane dyes to assess the morphology of MSCs inside the BMCP structure. Three days after the structure formation, cell expansion with "ejection" of processes and single intercellular contacts were registered within the BMCP-2 using phase contrast microscopy (Leica DMI 3000B, inverted microscope, Germany) (Figure 4 (a)). After $144 \mathrm{~h}$ (6 days) of BMCP-2 cultivation, we additionally observed the formation of intercellular contacts and an entire cell network (Figure 4 (b)). Staining with the fluorochrome Chromophilic Tracers-DiO DiOC14(3) 

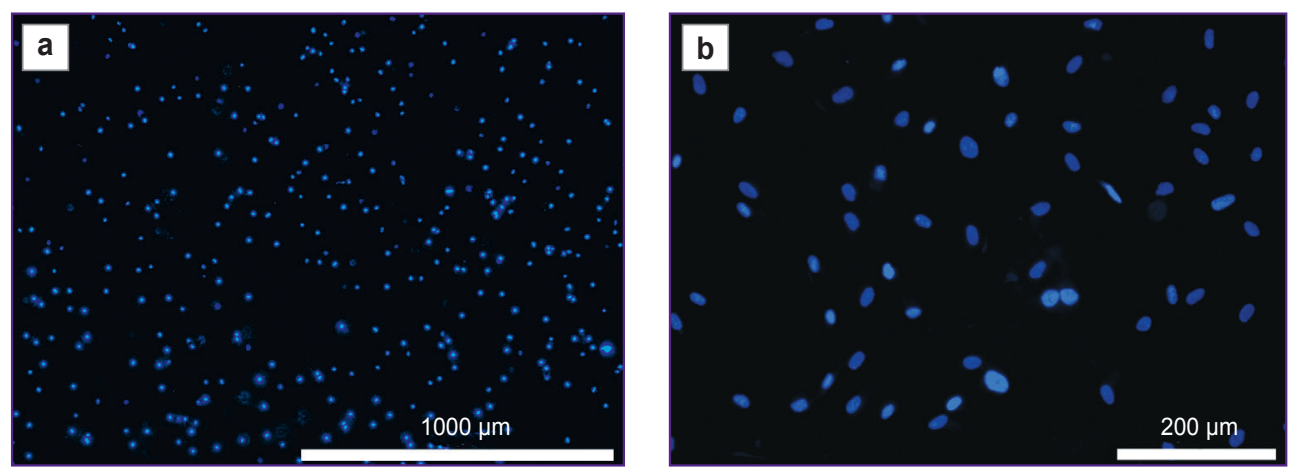

Figure 3. Crosslinked Z-stack microphotographs of cell nuclei (blue staining) from the bulk of BMCP-2:

(a) Z-stack at $530 \mu \mathrm{m}, 24 \mathrm{~h}$ of cultivation; (b) Z-stack at $300 \mu \mathrm{m}, 72 \mathrm{~h}$ of cultivation; fluorescence microscopy with Hoechst 3334 fluorochrome, excitation $-377 \mathrm{~nm}$, emission $-447 \mathrm{~nm}$; (a) ×40; (b) $\times 100$

Table 2

The numbers of adipose tissue MSCs contained in BMCP-2 during cultivation $\left(\mathrm{mm}^{3}\right)(\mathrm{M} \pm \mathrm{m})$

\begin{tabular}{|c|c|c|c|c|c|}
\hline \multirow{2}{*}{$\begin{array}{l}\text { Culture } \\
\text { No. }\end{array}$} & \multirow{2}{*}{$\begin{array}{c}\text { Number of samples/ } \\
\text { vision field }\end{array}$} & \multicolumn{3}{|c|}{ Time of cultivation (h) } & \multirow{2}{*}{$\begin{array}{l}\text { Cells } \\
\text { under the samples }\end{array}$} \\
\hline & & 24 & 72 & 144 & \\
\hline 1 & $5 / 50$ & $277.58 \pm 6.08$ & $610.01 \pm 14.21^{*}$ & $1115.54 \pm 26.59^{*+}$ & - \\
\hline 2 & $5 / 50$ & $347.0 \pm 10.48$ & $483.37 \pm 7.69^{*}$ & $530.90 \pm 10.37^{*+}$ & - \\
\hline 3 & $5 / 50$ & $200.60 \pm 5.02$ & $255.23 \pm 14.48$ & $393.31 \pm 13.64^{*+}$ & - \\
\hline
\end{tabular}

${ }^{*} \mathrm{p}<0.05$ - for comparison with 1 day culture $(24 \mathrm{~h}) ;{ }^{+} \mathrm{p}<0.05$ - for comparison with 3 day culture (72 h); Wilcoxon test.
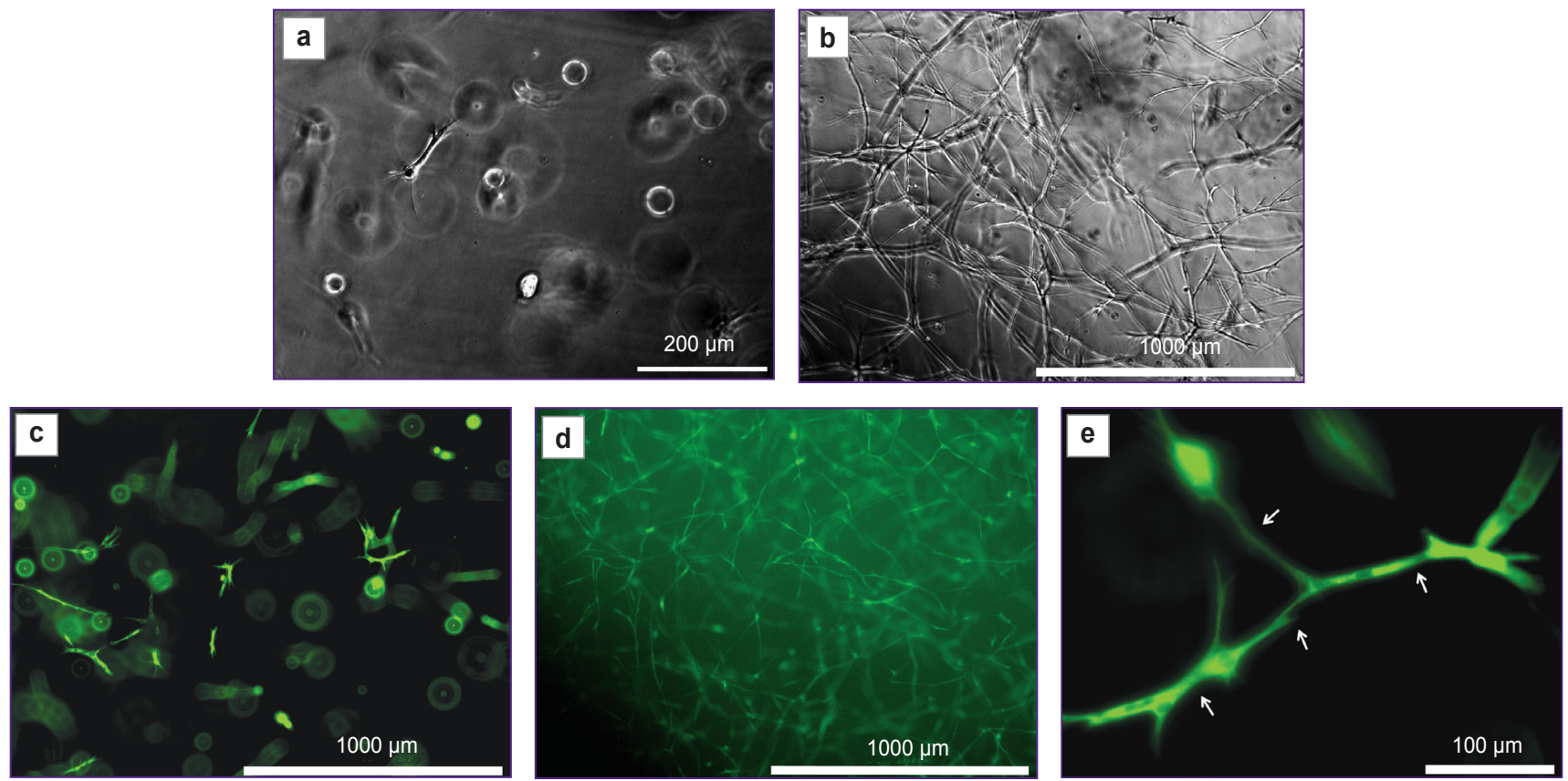

Figure 4. MSCs in the structure of BMCP-2:

(a), (b) phase contrast microscopy; (c)-(e) fluorescence microscopy; MSCs are stained with Lipophilic Tracers-DiO membrane green dye (excitation - $477 \mathrm{~nm}$, emission - $525 \mathrm{~nm}$ ); (a), (c) $24 \mathrm{~h}$ after the formation of BMCP-2: MSCs straighten and form processes; (a) $\times 100$; (c) $\times 40$; (b), (d) $120 \mathrm{~h}$ after the formation of BMCP-2: a recently formed cell network is seen $(\times 40)$; (e) 120 $\mathrm{h}$ of cultivation $(\times 100)$; spindle-shaped cells and intercellular contacts can be seen (arrows) 
Table 3

Concentrations of VEGF-A in the growth medium with BMCP-1 and with plastic plates (pg/ml) $(\mathrm{M} \pm \mathrm{m})$

\begin{tabular}{cccccccc}
\hline $\begin{array}{c}\text { Experiment } \\
\text { No. }\end{array}$ & \multicolumn{3}{c}{24} & \multicolumn{3}{c}{ Time of cultivation $(\mathrm{h})$} \\
& G-derm (BMCP-1) & Plastic & G-derm (BMCP-1) & Plastic & G-derm (BMCP-1) & Plastic \\
\hline 1 & $1497.5 \pm 72.3$ & $1342.2 \pm 100.4$ & $2408.2 \pm 182.0^{*}$ & $1896.0 \pm 79.0^{+}$ & $3395.3 \pm 264.5^{*}$ & $2159.9 \pm 42.8^{+}$ \\
\hline 2 & $1532.4 \pm 60.9$ & $488.5 \pm 29.1$ & $2347.3 \pm 82.6^{*}$ & $787.2 \pm 28.2^{+}$ & $3327.8 \pm 122.8^{* v}$ & $1056.8 \pm 30.5^{+\#}$ \\
\hline 3 & $375.8 \pm 31.8$ & $177.4 \pm 6.2$ & $593.5 \pm 22.8^{*}$ & $253.2 \pm 8.6^{+}$ & $878.0 \pm 39.7^{* v}$ & $334.9 \pm 9.2^{+\#}$ \\
\hline
\end{tabular}

* $p<0.05$ - for comparison with G-derm (24 h); v p <0.05 - for comparison with G-derm (48 h); ${ }^{+} p<0.05$ - for comparison with plastic (24 h); ${ }^{\#} \mathrm{p}<0.05$ — for comparison with plastic $(48 \mathrm{~h})$; Wilcoxon test.

Hydroxyethanesulfonate (green) confirmed the cell viability at this time period (Figure 4 (c), (d)); the cells were evenly spread throughout the BMCP-2 structure, thus forming a cell network. At $\times 200$ magnification (Figure 4 (e)), fusiform, fibroblast-like cells with pronounced processes and intercellular contacts were well visualized.

The results indicated that the adipose tissue MSCs preserved their viability and typical fibroblast-like morphology both on the BMCP-1 surface and in the BMCP-2 structure, although the cell distribution patterns differed between these two products.

Mesenchymal stem cells are substrate-dependent and, like other such cells, upon passage and separation from the matrix, they grow as a suspension rather than a monolayer. In this case, the cells change their morphology and become round-shaped. As a result, to assess the morphology of the cellular component of BMCP, which contains substrate-dependent cells, it would be necessary to cultivate them on a plastic surface for at least $24 \mathrm{~h}$ after isolation. In this study though, the fluorescence microscopy and the vital dyes made it possible to visualize and characterize the cell component of BMCP using a small fragment of the sample without destroying its structure. In addition, this approach allowed us to evaluate not only the viability, but also the morphology of the cells and their distribution on the surface and/or inside the BMCP structure.

Determination of the functional (secretory) activity of the cellular component of BMCP. In three series of experimentation with BMCP-1, we used three different lines of MSCs with different activities of the VEGF secretion. Nevertheless, in all three series, we observed a significant increase in the levels of VEGF-A in the growth medium. Moreover, the amount of protein determined during the cell growth on the surface of the G-derm plate (as part of BMCP-1) was significantly higher $(p<0.05$, Wilcoxon test) than that in cells grown on the plastic surface (Table 3).

The similar experiments with the BMCP-2 demonstrated a gradual increase in VEGF-A in the growth medium starting from the $3^{\text {rd }}$ day $(72 \mathrm{~h})$ in all series of the study (Table 4). In the control series (cellfree scaffolds), no changes in VEGF-A were found.
Table 4

Concentrations of VEGF-A in the growth medium with BMCP-2 (pg/ml) $(\mathrm{M} \pm \mathrm{m})$

\begin{tabular}{cccc}
\hline $\begin{array}{c}\text { Experiment } \\
\text { No. }\end{array}$ & \multicolumn{3}{c}{ Time of cultivation (h) } \\
\cline { 2 - 4 } 1 & $2129.3 \pm 22.8$ & $9521.9 \pm 794.9^{*}$ & $20754.1 \pm 971.7^{\star \mathrm{v}}$ \\
\hline 2 & $1874.9 \pm 40.6$ & $3661.5 \pm 189.9^{*}$ & $6087.7 \pm 111.4^{\star \mathrm{v}}$ \\
\hline 3 & $1698.9 \pm 90.6$ & $2660.9 \pm 105.6^{*}$ & $3620.1 \pm 107.9^{\star \mathrm{v}}$ \\
\hline
\end{tabular}

* $p<0.05$ - for comparison with the 3 day culture $(72 \mathrm{~h})$; ${ }^{v} \mathrm{p}<0.05$ - for comparison with the 5 day culture $(120 \mathrm{~h})$; Wilcoxon test.

According to these results, adipose tissue MSCs maintained the functional activity and VEGF-A secretion in both the BMCP-1 and BMCP-2 structures.

VEGF is a key angiogenic factor [9], which, like other growth factors, is synthesized by MSCs both in vitro and in vivo $[10,11]$. In addition to stimulating the angiogenesis, this protein triggers the proliferation and migration of endothelial cells and increases the permeability of blood vessels. In different BMCPs, non-cellular components have different physical characteristics (e.g., stiffness), which may affect the ability of MSCs to secrete VEGF [12]. Accordingly, the VEGF-A level in adipose tissue MSCs can serve as a criterium for assessing the quality of a BMCP, specifically, the preservation of the functional activity of MSCs contained in its structure. Using the proposed approach, we were able to evaluate the secretory activity of adipose tissue MSCs held inside the BMCP structure without its destruction and by using a minute volume of the growth medium. It should be noted that the protein concentration in the growth medium can characterize the functional activity of MSCs as part of BMPC after cryopreservation, which is most likely to be required in clinical practice.

Identification of the cell line. Before starting the BMPC forming procedures, we made sure that the phenotype of the MSC lines met the ISCT requirements: the mesenchymal cell markers CD90, CD105, CD73, and CD44 were expressed by more than $95 \%$ of cells, 


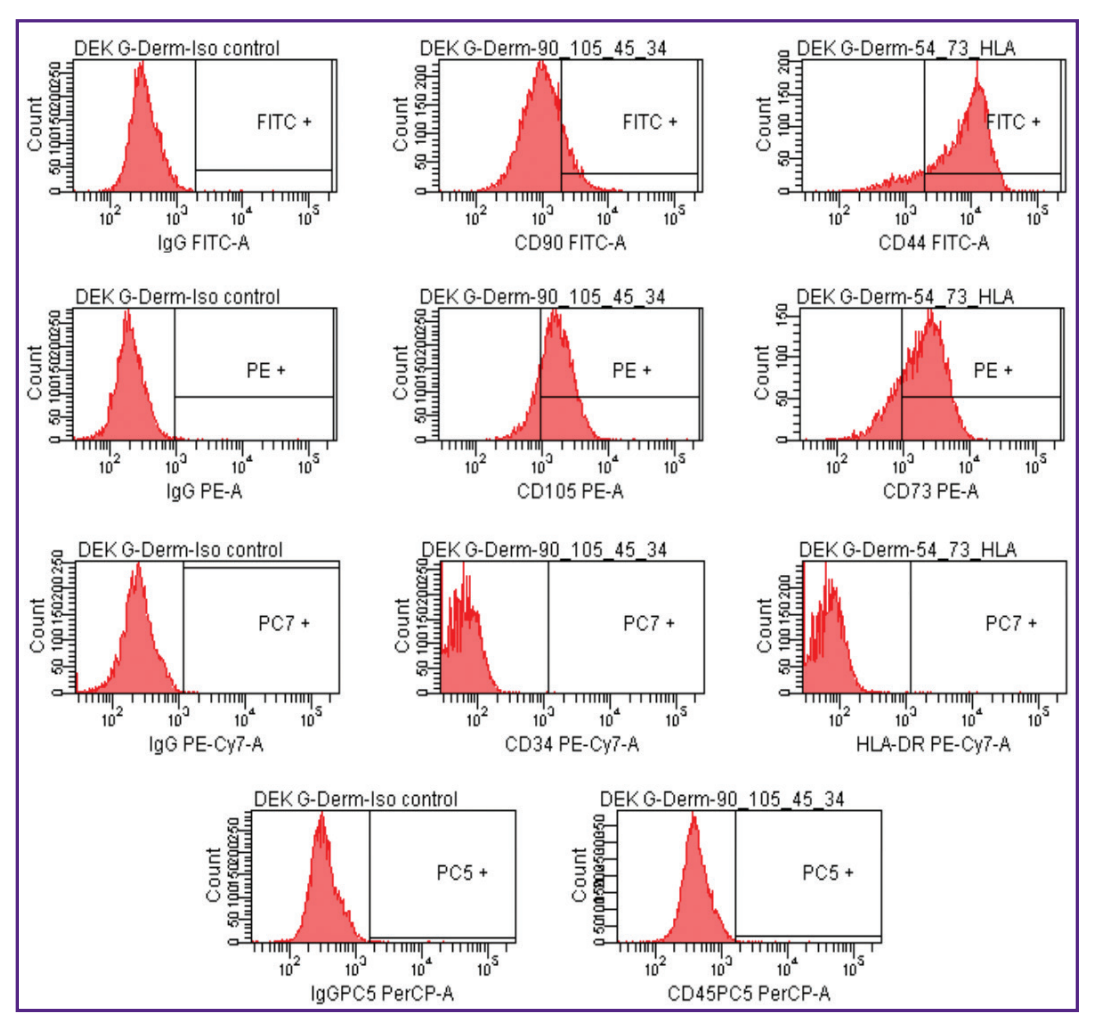

Figure 5. Immunophenotype of MSCs after isolation from BMCP-1: CD90 - 15.0\%; CD105 - 82.5\%; CD44 - 86.5\%; CD73 - 79.5\%; CD45 $0.3 \%$; CD34 - 0; CD HLA DR - 0.1\%
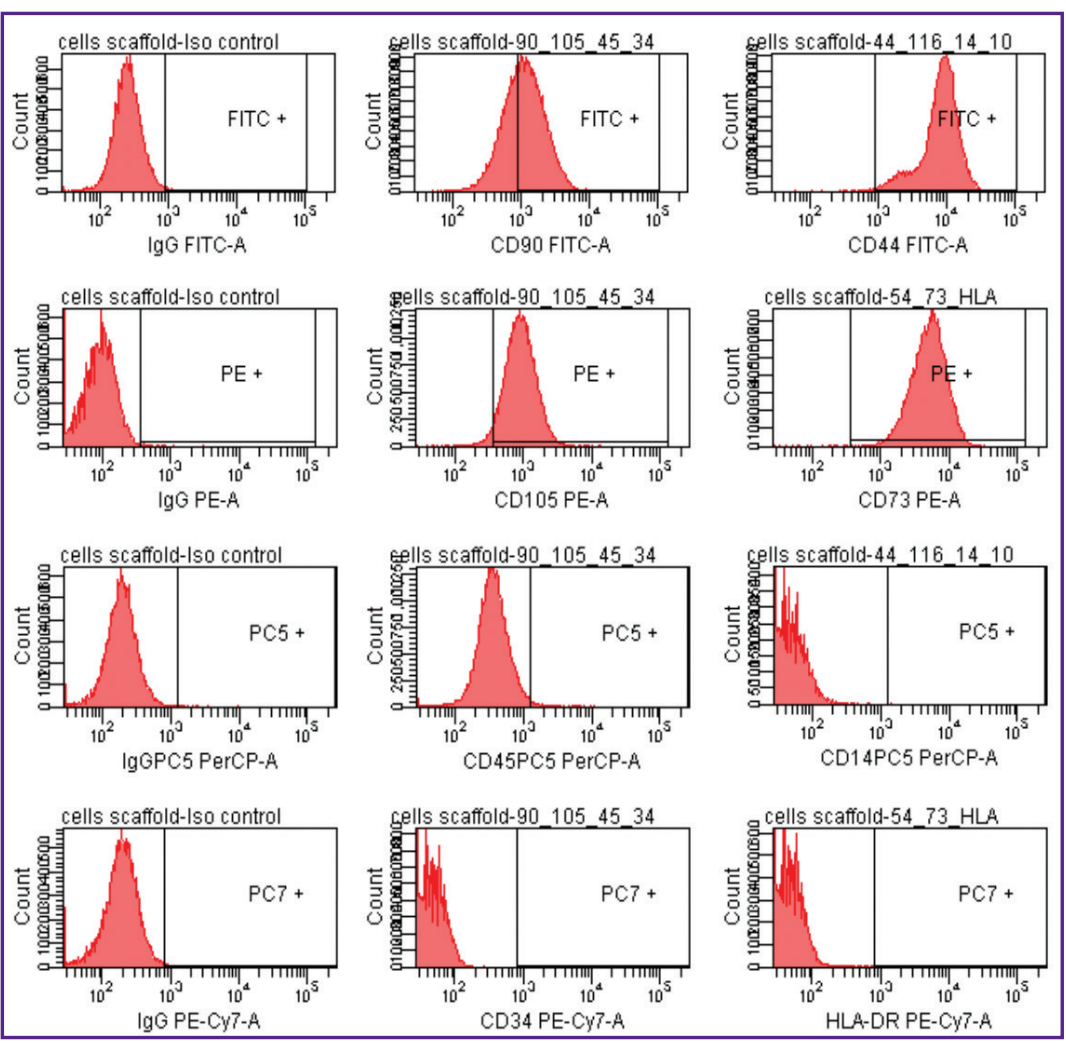

Figure 6. Immunophenotype of MSCs isolated from BMCP-2:

CD90 - 60\%; CD105 - 98\%; CD44 - 100\%; CD73 - 100\%; CD45 - 0; CD34 - 0; CD14 - 0; CD HLA DR - 0 and there was no expression of CD45, CD34, CD14, or CD HLA-DR.

We then found that the MSC phenotype changed after the cells were removed from the G-derm plate surface $48 \mathrm{~h}$ after the formation of BMCP-1 (Figure 5).

After the separation from the BMCP-1, a significant decrease in the number of $\mathrm{CD}^{+}$cells $(15-80 \%)$ and a slight decrease in the number of $\mathrm{CD}^{+} 3^{+}$and CD105 ${ }^{+}$cells were found. When cultured on the plastic surface under the standard conditions, cells isolated from BMCP-1 had their phenotype restored with a high proportion of specific markers CD90 99\%, CD105 - 99\%, CD73 - 99\%, CD44 - 99\% and with a low proportion of CD45 - 0.5\%, CD34 - 0, and CD HLA-DR - 0 .

MSCs cultured as part of BMCP-2 were isolated using collagenase treatment, which resulted in a significant (from 60 to $80 \%$ ) loss in CD90 ${ }^{+}$cells but no change in $\mathrm{CD}^{+} 3^{+}$and $\mathrm{CD} 105^{+}$cells (Figure 6).

After culturing for $96 \mathrm{~h}$ on the plastic, restoration of $95-96 \%$ of $\mathrm{CD}^{+} 0^{+}$cells was noted.

It can be assumed that the trend toward a decrease in the number of the marker-specific MSCs cultured in the medium-floating matrices may represent a response to the changed culture conditions during the transition from a 2D plate culture to an organotypic 3D culture incorporated in the BMCP [13]. This hypothesis is supported by the fact that within 1-3 days after being transferred from BMCP to regular plastic plates, the cells return to their original phenotype.

It should be noted that the development of MSCs as the cellular components of skin replacement BMCPs is one of the priority areas of today's regenerative medicine: a number of MSC-based products currently undergo preclinical and clinical studies [14, 15]. Within this context, the development of relevant assessment methods for MSCs as parts of various constructs is of growing importance. The present study showed, among other results, that two different BMPs having similar cellular compositions required somewhat different approaches to characterize their cellular components. 


\section{Conclusion}

In this study, we propose an approach to assessing the quality of biomedical cell products while considering their production and transportation as well as their cellular and non-cellular composition. Specifically, we conclude that for non-transparent and/or multicomponent products, it is advisable to choose the quality control methods involving a minimal treatment by proteolytic enzymes.

Research funding. This study was supported by the Ministry of Education and Science of the Russian Federation within the framework of a research program "Development of manufacturing, storage and application technologies for biomedical cell products for wound healing"; the unique project identifier RFMEFI61017X0012.

Conflict of interest. The authors have no conflict of interest.

\section{References}

1. Pyatigorskaya N.V., Tulina M.A., Aladysheva Zh.I., Beregovykh V.V. International approaches to the regulation of cell therapy products. Vestnik Rossiiskoi akademii meditsinskikh nauk 2013; 68(8): 4-8.

2. Federal'nyy zakon RF ot 23 iyunya 2016 g. No.180-FZ "O biomeditsinskikh kletochnykh produktakh" [Federal Law of the Russian Federation dated June 23, 2016 No.180-FZ "About biomedical cell products"].

3. Prikaz Ministerstva zdravookhraneniya Rossiyskoy Federatsii ot 08.08.2018 g. No.512n "Ob utverzhdenii Pravil nadlezhashchey praktiki po rabote s biomeditsinskimi kletochnymi produktami" [Order of the Ministry of Health of the Russian Federation dated August 8, 2018, No.512n "On the approval of the Rules of good practice for working with biomedical cellular products"].

4. Metodicheskie rekomendatsii po provedeniyu doklinicheskikh issledovaniy biomeditsinskikh kletochnykh produktov [Guidelines for preclinical studies of biomedical cell products]. Pod red. Tkachuka V.A. [Tkachuk V.A. (editor)]. Moscow: MGU im. M.V. Lomonosova; 2017; 302 p.

5. Egorikhina M.N., Levin G.Ya., Charykova I.N., Aleynik D.Ya., Sosnina L.N. Method for creating a bioresorbable cellular scaffold based on fibrin of blood plasma. Patent RU 2653434. 2018.

6. Granero-Molto F., Weis J.A., Longobardi L., Spagnoli A. Role of mesenchymal stem cells in regenerative medicine: application to bone and cartilage repair. Expert Opin Biol Ther 2008; 8(3): 255-268, https://doi. org/10.1517/14712598.8.3.255.

7. Dominici M., Le Blanc K., Mueller I., SlaperCortenbach I., Marini F., Krause D., Deans R., Keating A., Prockop D.J., Horwitz E. Minimal criteria for defining multipotent mesenchymal stromal cells. The International Society for Cellular Therapy position statement. Cytotherapy 2006; 8(4): 315-317, https://doi.org/10.1080/14653240600855905.

8. Egorikhina M.N., Charykova I.N., Aleynik D.Ya. Method of quantitative analysis of cellular components of scaffold. Patent RU 2675376. 2018.

9. Ferrara N., Davis-Smyth T. The biology of vascular endothelial growth factor. Endocr Rev 1997; 18(1): 4-25, https://doi.org/10.1210/edrv.18.1.0287.

10. Nakagami H., Maeda K., Morishita R., Iguchi S., Nishikawa T., Takami Y., Kikuchi Y., Saito Y., Tamai K., Ogihara T., Kaneda Y. Novel autologous cell therapy in ischemic limb disease through growth factor secretion by cultured adipose tissue-derived stromal cells. Arterioscler Thromb Vasc Biol 2005; 25(12): 2542-2547, https://doi. org/10.1161/01.atv.0000190701.92007.6d.

11. Rehman J., Traktuev D., Li J., Merfeld-Clauss S., Temm-Grove C.J., Bovenkerk J.E., Pell C.L., Johnstone B.H., Considine R.V., March K.L. Secretion of angiogenic and antiapoptotic factors by human adipose stromal cells. Circulation 2004; 109(10): 1292-1298, https://doi. org/10.1161/01.cir.0000121425.42966.f1.

12. Nasser M., Wu Y., Danaoui Y., Ghosh G. Engineering microenvironments towards harnessing pro-angiogenic potential of mesenchymal stem cells. Mater Sci Eng C Mater Biol Appl 2019; 102: 75-84, https://doi.org/10.1016/j. msec.2019.04.030.

13. Reisbig N.A., Hussein H.A., Pinnell E., Bertone A.L. Evaluation of equine synovial-derived extracellular matrix scaffolds seeded with equine synovial-derived mesenchymal stem cells. Am J Vet Res 2018; 79(1): 124-133, https://doi. org/10.2460/ajvr.79.1.124.

14. Lee H.C., An S.G., Lee H.W., Park J.S., Cha K.S., Hong T.J., Park J.H., Lee S.Y., Kim S.P., Kim Y.D., Chung S.W., Bae Y.C., Shin Y.B., Kim J.I., Jung J.S. Safety and effect of adipose tissue-derived stem cell implantation in patients with critical limb ischemia: a pilot study. Circ J 2012; 76(7): 17501760, https://doi.org/10.1253/circj.cj-11-1135.

15. Wu S.C., Pollak R., Frykberg R.G., Zhou W., Karnoub M., Jankovic V., Fischkoff S.A., Chitkara D. Safety and efficacy of intramuscular human placenta-derived mesenchymal stromal-like cells (cenplacel [PDA-002]) in patients who have a diabetic foot ulcer with peripheral arterial disease. Int Wound J 2017. 14(5). 823-829, https: Ildoi. org/10.1111/iwj.12715. 